\title{
PKM Kelompok Usaha Terasi Desa Bonang Kecamatan Lasem dalam Upaya Menghadapi Permasalahan Cuaca
}

\author{
Rikah, Agustina Widodo \\ Sekolah Tinggi Ilmu Ekonomi YPPI Rembang \\ rickah83@gmail.com
}

Key word:

Shrimp paste, dryer and weather.

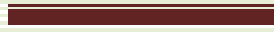

\section{Abstract}

The aim of the Community Partnership Program (PKM) is to increase community income through increased quality and quantity of shrimp paste production. This Partnership Program is business group of shrimp paste (rebon) in Bonang Village, Lasem Subdistrict, Rembang Regency with partners of shrimp paste craftsmen. The method carried out in the Community Partnership Program (PKM) is accompaniment to the group in understanding about the drying machine and get the information of capital provider. The realization of a drying machine that aims to ensure the continuity of the production process without having dependency by weather conditions and limited drying area. By using a shrimp paste drying machine, the group of shrimp paste craftsmen can still produce even in rainy and cloudy weather condition. The group of craftsmen can make product diversification, which is making ready-made cooked shrimp paste and be more hygienic by using shrimp paste drying machine.

\section{Abstrak}

\section{Kata Kunci}

Terasi udang rebon, alat pengering, cuaca
Tujuan dari Program Kemitraan Masyarakat (PKM) ini adalah untuk meningkatkan pendapatan masyarakat perbaikan kualitas dan kuantitas produksi terasi. Mitra pada kegiatan ini adalah Usaha terasi udang (rebon) di Desa Bonang, Kecamatan Lasem, Kabupaten Rembang dengan mitra kelompok pengrajin terasi Kakap dan Dorang Emas yang masih melakukan proses pengeringan terasi dilakukan dengan penjemuran sinar matahari. Metode yang dilakukan dalam PKM ini adalah dengan pendampingan terhadap kelompok untuk memahami mesin pengering dan akses modal. Hasil pengebdian adalah terealisasinya mesin pengering untuk terasi. Kelompok pengrajin terasi tetap dapat berproduksi meskipun dalam kondisi hujan dan cuaca yang mendung dengan bantuan mesin pengering terasi sehingga kelompok pengrajin terasi bisa membuat diversifikasi produk terasi, yaitu membuat terasi matang bubuk yang siap saji dan lebih higienis. 


\section{PENDAHULUAN}

Indonesia memiliki 17.508 pulau dan wilayah seluas $7.700 .000 \mathrm{~km} 2$. Selain itu Indonesia juga memiliki garis pantai terpanjang ke-4 di dunia yaitu +95.181 $\mathrm{km}$. Luas daratan Indonesia hanya 1/3 dari luas lautannya (Timnas Pembekuan Rupa Bumi, 2010).

Beberapa kelebihan yang dimiliki oleh negara Indonesia sebagai Negara maritim adalah berbagai potensi kelautan dan perikanan yang sangat melimpah, namun beberapa potensi tersebut masih belum digali secara optimal. Potensipotensi yang belum digali secara optimal tersebut di antaranya dari sektor pengolahan ikan. Salah satu hasil pengolahan ikan adalah terasi dari udang rebon.

Terasi merupakan salah satu bentuk produk industri olahan udang kecil (rebon). Terasi digunakan bahan pelengkap masakan yang sangat digemari oleh masyarakat, karena cita rasa khas dan nikmat. Terasi tidak hanya dijadikan bahan masakah tetapi sebagai sektor industri yang menghasilkan lapangan pekerjaan untuk meningkatkan ekonomi masyarakat lokal, karena dapat menyerap tenaga kerja, memberikan nilai tambah pada hasil laut yang berupa udang kecil (rebon) juga dapat menjadi sumber pendapatan bagi pemilik usaha kecil tersebut.
Salah satu desa di Kabupaten Rembang yang memiliki pengrajin terasi adalah Desa Bonang. Desa seluas 150Ha terletak di Kecamatan Lasem, Kabupaten Rembang. Secara geografis Desa Bonang terletak di sebelah Utara berbatasan dengan Laut Jawa, sebelah Selatan berbatasan dengan Desa Sriombo, sebelah Barat berbatasan dengan Desa Tasiksono, dan sebelah Timur berbatasan dengan Desa Binangun.

Jumlah penduduk Desa Bonang sebanyak 1.664 jiwa yang tersebar di 2 RW dan 5 RT. Sebagian besar penduduknya bekerja di sektor nelayan, pertanian, dan perdagangan. Desa Bonang Kecamatan Lasem terkenal dengan hasil perikanan sentra terasi dan ikan asin (BPS Kabupaten Rembang, 2016).

Hasil pra-survei menunjukkan di Desa Bonang terdapat 2 (dua) kelompok usaha terasi yaitu Kelompok Usaha Terasi Kakap dan Dorang Emas. Kegiatan yang dilakukan oleh kelompok usaha terasi Kakap dan Dorang Emas hanya sebatas pada pembuatan terasi udang (rebon) dengan metode olahan tradisional belum memiliki alat pengering. Karena belum mempunyai alat pengering, pengolahan terasi hanya dapat dilakukan dengan mengandalkan bantuan sinar matahari.

Hal ini akan sangat berpengaruh terhadap produksi dan kualitas terasi, 
karena pada musim penghujan para pengrajin terasi tidak dapat melakukan proses produksi. Sehingga ini akan menghambat produktivitas dan dari sisi ekonomi akan mengurangi tingkat pendapatan masyarakat desa Bonang.

Penggunaan alat pengering terasi ini, masyarakat kelompok pengrajin terasi dapat melakukan proses produksi setiap hari tanpa khawatir jika musim penghujan datang. Alat pengering terasi ini berfungsi untuk mengeringkan udang (rebon) yang diolah menjadi terasi agar waktu pengeringan lebih cepat dan tidak bergantung pada cuaca, sehingga produktivitas bisa ditingkatkan yang diharapkan akan dapat berimbas pada tingkat pendapatan masyarakat pengrajin terasi sehingga kesejahteraan dapat tercapai.

Berdasarkan uraian di atas, permasalahan yang dihadapi oleh kelompok usaha terasi Kakap dan Dorang Emas di Desa Bonang adalah hasil tangkapan laut di Desa Bonang sebagian besar langsung dijual oleh nelayan tanpa pengolahan lebih lanjut yang bisa menambah nilai jual udang kecil (rebon).

Selain itu, pengrajin terasi yang telah mengolah udang kecil (rebon) menjadi terasi menghasilkan produksi terasi yang masih rendah karena belum adanya alat pengering terasi.

\section{METODE PEMECAHAN MASALAH}

Metode pendekatan yang dilakukanoleh Tim untuk menyelesaikan permasalahan mitra salah satunya melakukan pelatihan dan pendampingan para melakukan sosialisasi kepada pengrajin terasi mengenai pentingnya dan manfaat ada kelompok jejaring pengrajin terasi di Desa Bonang Kecamatan Lasem Kabupaten Rembang.

Adapun bentuk pendampingan yang dilakukan oleh tim adalah:

1. Memfasilitasi teknologi produksi dengan alat pengering terasi. Alat ini berfungsi untuk mengeringkan udang (rebon) yang diolah menjadi terasi agar waktu pengeringan lebih cepat dan diharapkan akan dapat berimbas pada tingkat pendapatan masyarakat pengrajin terasi sehingga kesejahteraan dapat tercapai. Produksi tidak bergantung pada cuaca, sehingga produktivitas bisa ditingkatkan;

2. Membantu menjembatani antara pihak UMKM pengrajin terasi dengan pihakpihak jasa keuangan yang menawarkan fasilitas pinjaman modal lunak. Sehingga permasalahan modal bisa teratasi untuk bisa mengembangkan usaha;

3. Membantu UMKM pengrajin terasi untuk menciptakan inovasi-inovasi produk pengolahan hasil laut untuk 
diolah menjadi produk dengan jenis produk yang berbeda yang mempunyai nilai jual produk; dan

4. bermitra dengan institusi-institusi terkait baik pemerintah maupun swasta secara intens agar memberikan pembinaan dalam mengembangkan usaha sehingga dapat meningkatkan pendapatan para pengrajin terasi

\section{HASIL}

Luaran yang dihasilkan pada Program Kemitraan Masyarakat ini yaitu:

1. Perubahan mindset para pengrajin terasi dalam hal memanfaatkan kelompok pengrajin terasi dan jejaring serta men dukung ikon sebagai Desa Wisata Religi yang berorientasi pada keuntungan (profit oriented);

2. Kelompok usaha terasi mengenal penyedia modal (jasa keuangan) memperbaiki administrasi kelompok;

3. Diserahkannya mesin pengering terasi yang mampu meminimalkan lead time produksi. Alat pengering terasi ini terdiri dari: (1) regulator dan selang gas; (2) kran pengatur gas; (3) nozzle burner; (4) ruang tungku oven; (5) rak loyang; (6) loyang; (7) indikator temperatur; (8) pintu tungku oven; (9) kaca pengontrol; (10) pemantik manual; dan (11) timer manual.

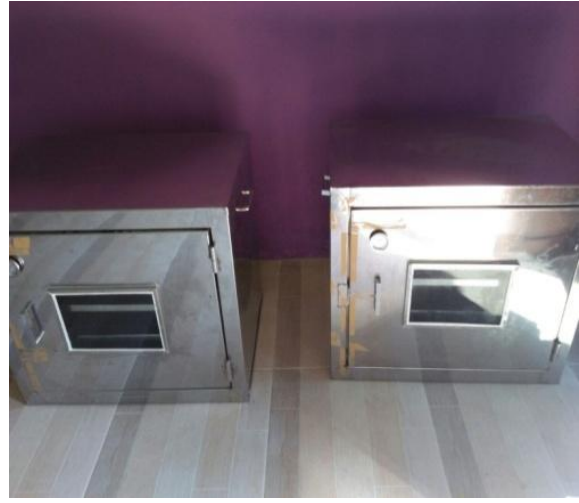

Gb 1. Mesin Pengering Terasi

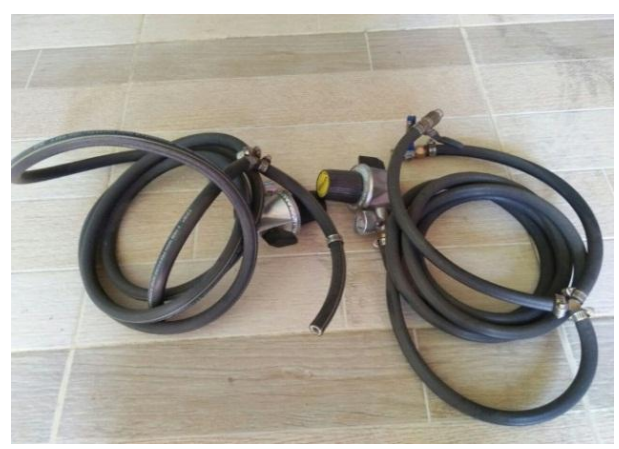

Gb 2. Selang Tabung Gas dan Regulator

\section{PEMBAHASAN}

Kegiatan PKM ini berbentuk pelatihan dan pendampingan para melakukan sosialisasi kepada pengrajin terasi mengenai pentingnya dan manfaat ada kelompok jejaring pengrajin terasi di Desa Bonang Kecamatan Lasem Kabupaten Rembang melalui tahapan sebagai berikut:

1. Persiapan

Tahap awal dalam pelaksanaan Program Kemitraan adalah melakukan survey pendahuluan kelokasi/daerah mitra. Survei dilakukan untuk mengetahui permasalahan mitra dan solusi bersama. 


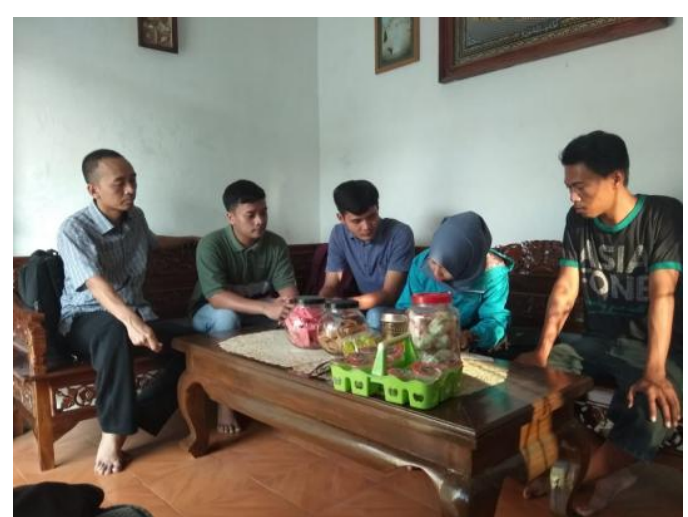

Gb. 3 Survey Awal Kegiatan Pengabdian

Hasil survey awal ini adalah terpilihnya dua kelompok usaha pengrajin terasi yang masih menggunakan cara tradisional dalam pengeringan, yaitu dengan sinar matahari dan pengemasan yang sederhana. Kelompok terasi yang terpilih beserta anggotanya kemudian menjadi mitra PKM yang akan menerima pelatihan dan penyuluhan dari tim pengabdi.

\section{Pelaksanaan}

Pelaksanaan pengabdian terdiri dari penyuluhan, pelatihan, dan pendampingan. Tim melakukan penyuluhan tentang pentingnya kelompok bagi pengrajin terasi yang dilanjutkan dengan memperkuat peran kelompok pada tanggal 2-4 Agustus 2018.

Materi yang diberikan pada penyuluhan ini adalah informasi mengenai kelebihan produksi terasi menggunakan alat pengering. Selain itu, tim juga memantik peserta untuk menggali lebih dalam potensinya untuk dapat memperoleh kerjasama permodalan dari penyedia modal.

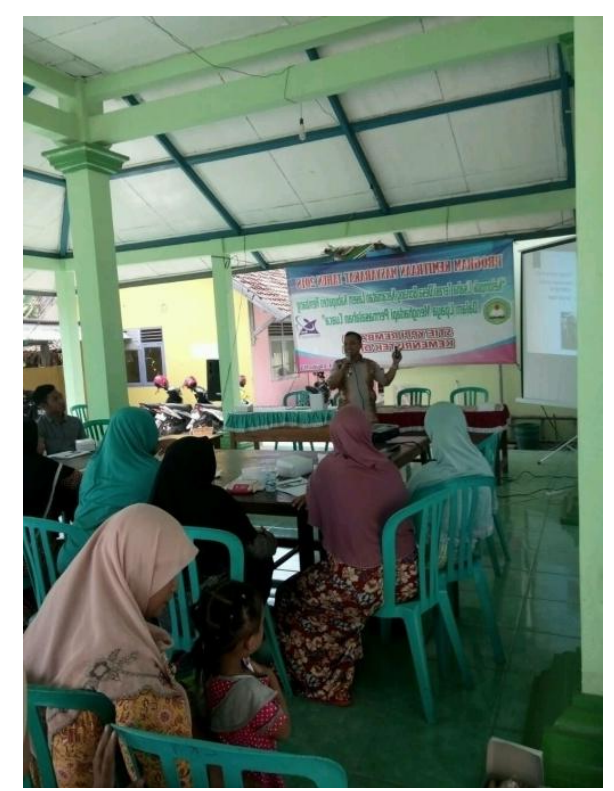

Gb 4. Penyuluhan Kelompok Usaha

Terasi

Peserta yang terdiri dari dua kelompok usaha mendapat pelatihan cara penggunaan mesin pengering terasi dan mempraktikkannya untuk dapat disupervisi oleh tim. Tim juga menyerahkan bantuan mesin pengering terasi untuk dua kelompok.

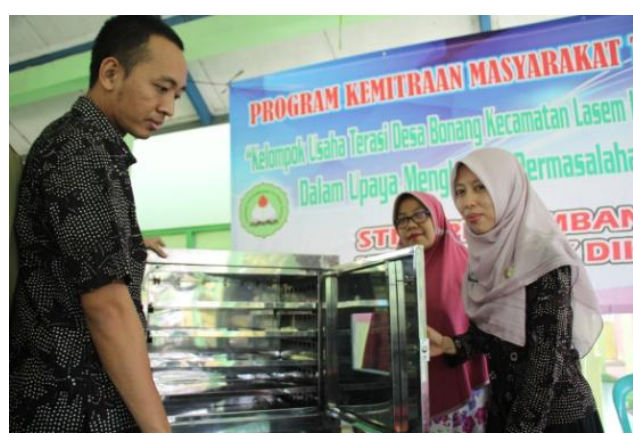

Gb 5. Penyerahan Mesin Pengering Terasi 
3. Evaluasi

Evaluasi dilaksanakan untuk mengetahui pelaksanaan Program Kemitraan Masyarakat (PKM) berjalan dengan lancar. Evaluasi dilaksanakan dengan cara melihat apakah materi pelatihan yang diberikan yaitu berupa pelatihan pemasaran (pemanfaatan teknologi), dalam peningkatan kualitas produksi serta manajemen usaha dan administrasi keuangan bisa dipahami, dimengerti, dipraktekkan, dan dilaksanakan oleh UKM terasi di Desa Bonang.

Evaluasi hasil produksi dengan alat pengering dengan memperhatikan beberapa komponen. Komponen yang dievaluasi dengan penerapan alat pengering pada usaha terasi ini adalah:

1. Aspek Produksi

Evaluasi aspek produksi dapat dilakukan melalui beberapa hal yaitu: (1) waktu pengeringan terasi lebih singkat sehingga proses produksi dikatakan lebih efektif; (2) kemampuan mesin dalam mengeringkan terasi dengan membandingkan berat terasi sebelum dan sesudah dikeringkan menunjukkan hasil yang sesuai dengan harapan kelompok usaha; (3) kemampuan/ kapasitas pengeringan mesin/ alat pengering terasi dengan membandingkan dengan pengeringan sinar matahari; dan (4) kualitas terasi hasil produksi dengan menggunakan alat ini dan dengan menggunakan sinar matahari.

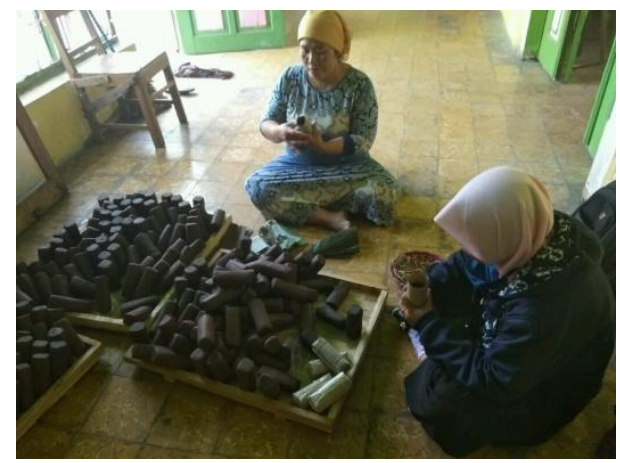

Gb 6. Pengemasan Terasi

2. Aspek Manajemen

Evaluasi aspek manajemen dapat dilakukan melalui beberapa hal yaitu: (1) tingkat kepuasan UKM dengan penerapan alat pengering terasi menunjukkan bahwa mitra puas dengan alat pengering; (2) tingkat pemahaman pekerja tentang operasional dan pemeliharaan alat pengering terasi menunjukkan bahwa kelompok usaha sangat memahami cara kerja alat dan cakap dalam pengoperasian; dan (3) evaluasi pendapatan UKM dengan adanya penerapan alat pengering terasi, hal ini belum dapat dilihat secara menyeluruh 


\section{SIMPULAN}

Hasil Program Kemitraan Masyarakat (PKM) pengrajin terasi Desa Bonang, Kecamatan Lasem, Kabupaten Rembang ini dapat disimpulkan dengan hal-hal sebagai berikut:

1. Kegiatan sosialisasi dilakukan pada anggota kelompok terasi Kakap dan Dorang Emas berkaitan dengan pentingnya peran kelompok dalam memajukan usaha terasi di Desa Bonang, Kecamatan Lasem, Kabupaten Rembang;

2. Alat pengering terasi ini juga dapat berfungsi untuk mengeringkan udang (rebon) yang diolah menjadi terasi agar waktu pengeringan lebih cepat dan diharapkan akan dapat berimbas pada tingkat pendapatan masyarakat pengrajin terasi sehingga kesejahteraan dapat tercapai.

3. Produksi tidak bergantung pada cuaca, sehingga produktivitas bisa ditingkatkan;

4. Kelompok usaha terasi memiliki jejaring dengan penyedia jasa keuangan dan mampu merapikan administrasi sebagai salah satu cara untuk mendapatkan pinjaman modal dari penyedia jasa keuangan.

\section{SARAN}

Pengabdian kepada kelompok terasi ini baru sebatas pemberian alat pengering dan pendampingan administrasi. Selanjutnya dibutuhkan pengabdian dan pendampingan agar hasil dari pengabdian ini dapat dilaksanakan secara kontinu dan secara bersamaan meningkatkan pendapatan pengrajin terasi. Topik pengabdian yang perlu diangkat selanjutnya adalah:

1. Pelatihan penyusunan portofolio untuk pengajuan pinjaman modal;

2. Pelatihan pengemasan terasi;

3. Pelatihan pemasaran terasi ke pasar yang lebih luas;

4. Pelatihan peningkatan kapasitas produksi dengan inovasi alat pengering atau mesin pembuat terasi

\section{UCAPAN TERIMAKASIH}

Tim pelaksana pengabdian mengucapkan terima kasih kepada STIE YPPI Rembang yang memberikan dana pengabdian, Kelompok Usaha Terasi Kakap dan Kelompok Usaha Terasi Dorang Emas Rembang yang telah menjadi mitra dalam pelaksanaan pengabdian ini, serta pihak terkait lain yang telah membantu selama kegiatan. 


\section{DAFTAR PUSTAKA}

Amin, M., \& Subri, M. (2017). Penggunaan Alat Pengering Untuk Mensuplay Bahan Baku Produksi Kripik Jagung di Grobogan. In Prosiding Seminar Nasional \& Internasional (Vol. 1, No. 1).

Badan Pusat Statistik Kabupaten Rembang. (2016). Kecamatan Lasem Dalam Angka, Dinas Kelautan dan Perikanan Kabupaten Rembang.

Balai Pengujian Mutu Alat dan Mesin Pertanian. (2012). Laporan Uji (Test Report) Mesin Pengering Biji Jagung - Merk MBI Model BP 4200 Tipe Bak Datar, Direktorat Mutu dan Standardisasi-Direktorat Jenderal Pengolahan dan Pemasaran Hasil Pertanian-Kementerian Pertanian.

Direktorat Penelitian dan Pengabdian Kepada Masyarakat, Direktorat Jenderal Pendidikan Tinggi, Kementerian Pendidikan dan Kebudayaan. (2016). Panduan PelaksanaanPenelitian dan an Tinggi, Edisi XI.

Fuad, M., Bulan, T., \& Chandra, R. (2018). Pendampingan Pembuatan Merek Usaha, Desain Kemasan Serta
Pengurusan IUMK Sebagai Upaya Penguatan Daya Saing Produk Terasi

Desa Simpang Lhee Kecamatan Langsa Barat - Kota Langsa. JATI EMAS (Jurnal Aplikasi Teknik Dan Pengabdian Masyarakat), 2(1), 1 - 8

Napitupulu, F. H., \& Tua, P. M. (2012). Perancangan dan Pengujian Alat Pengering Kakao dengan Tipe Cabinet Dryer untuk Kapasitas 7, 5 Kg Per-Siklus. Jurnal Dinamis, (10).

Nazaruddin, N., Arif, Z., Rinaldi, A., \& Zulfri, M. (2015). Kaji Eksperimental Pengering Surya Tipe Lorong Untuk Mengeringkan Terasi. Jurutera, 2(01), 77-84.

Purtomo, T., Ratih, I. A. B., \& Utomo, D. B. (2016). IbM Kelompok Usaha Rumah Tangga Terasi Rebon di Lingkungan Pantai Teleng Kota Pacitan. JPM17: Jurnal Pengabdian Masyarakat, 2(01).

Suprapti, M.L. (2002). Membuat Terasi (Teknologi Tepat Guna). Kanisius. Yogyakarta.

Surni, dkk. (2013). Packaging of an Instant "Terasi" for Diversified Marketing. World Applied Sciences Journal 
p-ISSN : 2548-8783

e-ISSN : 2548-8791

(Natural Resources Research and

Development in Sulawesi Indonesia)

vol 26 - PP 89-9 Tahun 2013. 